\section{State-of-the-art review: allogeneic stem cell transplantation for myelofibrosis in 2019}

Donal P. McLornan, ${ }^{1,2}$ Ibrahim Yakoub-Agha, ${ }^{3}$ Marie Robin, ${ }^{4}$ Yves Chalandon, ${ }^{5}$ Claire N. Harrison ${ }^{1,2 *}$ and Nicolaus Kroger ${ }^{6 *}$

${ }^{1}$ Guy's and St.Thomas' NHS Foundation Trust, Department of Haematology, Guy's Tower, Great Maze Pond, London, UK; ${ }^{2}$ Comprehensive Cancer Centre, King's College, London, UK; ${ }^{3} \mathrm{CHU}$ de Lille, LIRIC, INSERM U995, Universite de Lille, France; ${ }^{4}$ Hôpital Saint-Louis, Service d'Hématologie-Greffe, Assistance Publique Hôpitaux de Paris, University Paris 7, INSERM 1131, France; ${ }^{5}$ Geneva University Hospitals, Division of Hematology, Rue GabriellePerret-Gentil 4 and Faculty of Medicine, University of Geneva, Switzerland and ${ }^{6}$ University Hospital Eppendorf, Hematology Department, Hamburg, Germany

$\mathrm{CNH}$ and NK: joint senior authors

\section{ABSTRACT}

A dvances in understanding the pathogenesis and molecular landscape of myelofibrosis have occurred over the last decade. Treating physicians now have access to an ever-evolving armamentarium of novel agents to treat patients, although allogeneic hematopoietic stem cell transplantation remains the only curative approach. Improvements in donor selection, conditioning regimens, disease monitoring and supportive care have led to augmented survival after transplantation. Nowadays, there are comprehensive guidelines concerning allogeneic hematopoietic stem cell transplantation for patients with myelofibrosis. However, it commonly remains difficult for both physicians and patients alike to weigh up the risk-benefit ratio of transplantation given the inherent heterogeneity regarding both clinical course and therapeutic response. In this timely review, we provide an up-to-date synopsis of current transplantation recommendations, discuss usage of JAK inhibitors before and after transplantation, examine donor selection and compare conditioning platforms. Moreover, we discuss emerging data concerning the impact of the myelofibrosis mutational landscape on transplantation outcome, peri-transplant management of splenomegaly, poor graft function and prevention/management of relapse.

\section{Introduction}

Myelofibrosis is a heterogeneous disease as regards both disease phenotype and mutational landscape. Following the discovery of the JAK $2^{\mathrm{V} 61 \mathrm{~F}}$ mutation in 2005 and subsequent studies confirming the clinical efficacy of JAK inhibitors, the treatment paradigm has been revolutionized. ${ }^{1.6}$ Worldwide experience with JAK inhibitor therapy continues to grow and a considerable proportion of patients will gain beneficial symptom and/or splenic responses, albeit heterogeneous and of variable duration. Furthermore, given that many other novel therapeutics, such as anti-fibrotic and immunomodulatory agents, have been used to treat myelofibrosis, ${ }^{7}$ the majority of patients moving forward with allogeneic hematopoietic stem cell transplantation (SCT) have had at least one prior treatment, making 'realworld' transplant decisions increasingly complex. Data from the European Society for Blood and Marrow Transplantation (EBMT) suggest a year-on-year increase in transplants for myelofibrosis. In this review we focus on current indications for allogeneic SCT, prognostic scoring models to aid decision-making, donor selection, conditioning regimens, the role of splenectomy and prevention and management of relapse.
Haematologica 2019

Volume 104(4):659-668

\section{Correspondence:}

DONAL P MCLORNAN

donal.mclornan@nhs.net

Received: September 9, 2018.

Accepted: November 16, 2018.

Pre-published: March 14, 2019.

doi:10.3324/haematol.2018.206151

Check the online version for the most updated information on this article, online supplements, and information on authorship \& disclosures: www.haematologica.org/content/104/4/659

(C)2019 Ferrata Storti Foundation

Material published in Haematologica is covered by copyright. All rights are reserved to the Ferrata Storti Foundation. Use of published material is allowed under the following terms and conditions:

https://creativecommons.org/licenses/by-nc/4.0/legalcode. Copies of published material are allowed for personal or internal use. Sharing published material for non-commercial purposes is subject to the following conditions:

https://creativecommons.org/licenses/by-nc/4.0/legalcode, sect. 3. Reproducing and sharing published material for commercial purposes is not allowed without permission in writing from the publisher. 


\section{The transplant decision: how to decide who should be considered for allogeneic stem cell transplantation}

\section{Utilization of established and novel prognostic scoring systems in myelofibrosis}

Clinical prognostic scoring systems play a pivotal role in decisions regarding allogeneic SCT. Until recently, the most commonly applied was the International Prognostic Scoring System (IPSS) which estimates survival from time of diagnosis. ${ }^{8}$ The score is based upon five factors: age $>65$ years, hemoglobin $<100 \mathrm{~g} / \mathrm{L}$, leukocyte count $>25 \times 10^{9} / \mathrm{L}$, circulating blasts $\geq 1 \%$ and constitutional symptoms, permitting stratification into four groups: low risk (0 risk factors; estimated median survival, 135 months), intermediate risk-1 (1 risk factor; median survival, 95 months), intermediate risk2 (2 risk factors, median survival, 48 months) and high risk (3+ risk factors; median survival, 27 months). The Dynamic IPSS (DIPSS), utilizing the same five factors, permits application of the scoring system at any stage in the disease course. ${ }^{9}$ Finally, the DIPSS-plus incorporates three additional adverse factors - transfusion dependency; platelet count $<100 \times 10^{9} / \mathrm{L}$ and unfavorable cytogenetics. ${ }^{10,11} \mathrm{We}$ follow current European LeukemiaNet/EBMT expert consensus whereby "Patients with intermediate-2- or high-risk disease according to the IPSS, DIPSS or DIPSS-plus and age $<70$ years should be considered potential candidates for allogeneic SCT". ${ }^{2}$ Patients with "intermediate-1-risk disease and age $<65$ years should be considered as candidates if they present with either refractory, transfusion-dependent anemia, or a percentage of blasts in peripheral blood $>2 \%$, or adverse (as defined by the DIPSS-plus classification) cytogenetics". Decisions regarding transplantation for intermediate-1-risk disease remain complex and are discussed below.

A retrospective, comparative multicenter outcome analysis of 438 patients with primary myelofibrosis aged $<65$ years at diagnosis who underwent allogeneic SCT $(n=190)$ or conventional therapy in the era before JAK inhibitors ( $n=248)$, utilizing DIPSS scoring, demonstrated that allogeneic SCT clearly benefited intermediate-2 or high-risk patients whereas for low-risk disease, transplantation is not immediately indicated and is held in reserve for progressive disease. ${ }^{13}$ For intermediate- 1 disease, individual counseling was recommended. Despite evident utility, marked heterogeneity may be observed within each allocated IPSS/DIPSS subgroup. Grinfeld et al. performed genomic and clinical phenotype analyses of 2,041 patients with myeloproliferative neoplasms, including 311 with myelofibrosis, and combined the findings into a unifying patient-specific predictive model. ${ }^{14}$ For myelofibrosis, this model predicted event-free survival better than did either the DIPSS or IPSS ( $81 \%$ versus $69 \%$ versus $77 \%$ concordance) and an online calculator is being developed for predicting patient-specific outcomes (https://jg738.shinyapps.io/mpn_app/). It will be of interest to apply this model to a population of myelofibrosis patients undergoing allogeneic SCT.

A collaborative group recently studied 685 molecularlyannotated patients with secondary myelofibrosis to assess whether an independent prognostic scoring system could be derived. ${ }^{15}$ The so-called MYelofibrosis SECondary to PV and ET-Prognostic Model (MYSEC-PM) allocated individuals into four prognostic categories based on negative predictors of survival whereby two points were attributed to hemoglobin $<110 \mathrm{~g} / \mathrm{dL}$, a CALR-unmutated phenotype and circulating blasts $\geq 3 \%$, one point to thrombocytopenia
$<150 \times 10^{9} / \mathrm{L}$ and constitutional symptoms and 0.15 points to any year of age. Median survival estimates for each group ranged from not reached in the low-risk cohort to 2 years in high-risk cohorts. Akin to IPSS/DIPSS, recent analyses suggested that transplant-specific age-adjustment of the MYSEC-PM provided prognostic predictive power as regards overall survival following allogeneic SCT. ${ }^{16-18}$

\section{The role of mutational profiling in allogeneic stem cell transplant decisions}

Comprehensive mutational profiling has helped identify heterogeneous somatic mutations in patients with myelofibrosis. Delineation of this mutational landscape confers prognostic significance as regards overall survival and risk of disease progression/transformation and increasingly influences therapeutic decisions (Table 1). ${ }^{19-22}$ In the nontransplant setting, it is well established that myelofibrosis patients with $C A L R$ type-1/like mutations survive longer than patients with CALR type-2/like and MPL or JAK2 mutations. ${ }^{21}$ 'Triple negativity', i.e. lacking a detectable $J A K 2, M P L$ or CALR mutation, is associated with more adverse outcomes. Previous analyses of 617 myelofibrosis patients revealed that the median survival was only 3.2 years for those who were 'triple negative'.$^{19}$ Conventionally, high molecular risk myelofibrosis is defined by the presence of at least one of EZH2, ASXL1, IDH1/2 and SRSF2 mutations and is associated with worse overall and leukemiafree survival. ${ }^{22}$

These data raise the question of whether earlier transplantation should be considered for those who have "triple negative' disease, particularly with high molecular risk mutations, and need to be taken into consideration when counseling patients, particularly transplant-eligible individuals with intermediate-1-risk disease and 'good' donors. Recently, Guglielmelli and colleagues described the utility of both the mutation-enhanced IPSS 'MIPSS70' and 'MIPSS70-plus' (including cytogenetic evaluation) scoring systems for 'transplant-age' patients $\leq 70$ years old with either pre-fibrotic or overt, primary myelofibrosis who were considered candidates for transplantation. ${ }^{23}$ Significant risk factors for overall survival were leukocyte count $>25 \times 10^{9} / \mathrm{L}$, platelet count $<100 \times 10^{9} / \mathrm{L}$, presence of $>2$ high molecular risk mutations, hemoglobin $<100 \mathrm{~g} / \mathrm{L}$, peripheral blood blasts $\geq 2 \%$, constitutional symptoms, high molecular risk category, fibrosis grade $>2$ and absence of CALR type$1 /$ like mutations. These scoring systems enabled three discrete prognostic risk categories to be delineated: low-risk, intermediate-risk and high-risk with 5-year survival rates of $95 \% ; 70 \%$ and $29 \%$, respectively. The MIPSS70-plus included cytogenetics in the multivariable analysis. Recent updates to 'MIPSS70-plus version 2' occurred with recognition of $U 2 A F 1^{a 157}$ as a high molecular risk mutation and the scoring system uses new sex- and severity-adjusted hemoglobin thresholds. ${ }^{24}$ Importantly these scores incorporate current molecular data and up-to-date WHO 2016 disease classification and will aid decisions regarding allogeneic SCT.

It can be difficult when a clinician is managing a young, fit patient with myelofibrosis who has intermediate risk-1 disease and a fully matched donor. Should we transplant upfront when the patient is fit, and the donor is available or should we wait for further disease upstaging before considering allogeneic SCT? Collectively, we feel that this is a very individualized choice, and has many strata including the patient's wishes and donor type, disease-associated 
Table 1. Key characteristics of pivotal non-JAK2/CALR or MPL mutations in myelofibrosis.

Chromosome Characteristics Reference

\section{Spliceosome mutations}

\begin{tabular}{|c|c|c|c|}
\hline \multirow{4}{*}{ SRSF2 } & \multirow{4}{*}{$17 q 25.1$} & - Mutations reported in up to $17 \%$ of PMF & \multirow{4}{*}{70} \\
\hline & & - Commonly monoallelic mutations affecting residue P95 & \\
\hline & & - More common in older age, higher DIPSS-plus group, accompanying IDH mutations & \\
\hline & & • Associated with worse outcome: OS and LFS & \\
\hline \multirow{3}{*}{$U 2 A F 1$} & \multirow{3}{*}{$21 \mathrm{q} 22.3$} & - Involved in pre-mRNA splicing & \multirow{3}{*}{71,72} \\
\hline & & - Mutations reported in up to $16 \%$ of PMF & \\
\hline & & - Mutations associated with older age; normal karyotype; anemia and thrombocytopenia & \\
\hline \multirow{3}{*}{ SF3B1 } & \multirow{3}{*}{$2 q 33.1$} & • Incidence of around 6\% & \multirow{3}{*}{73} \\
\hline & & - More common with bulky splenomegaly & \\
\hline & & - Presence does not appear to influence survival & \\
\hline
\end{tabular}

\section{Chromatin modifications}

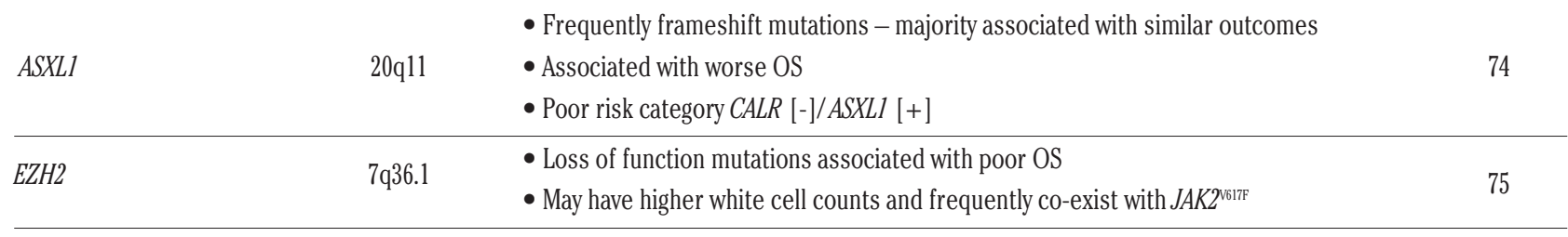

\section{Other}

$\begin{array}{lcl}\text { IDH1 } & 2 \mathrm{q} 33.3 & \bullet \text { Clusters with older age } \\ I D H 2 & 15 \mathrm{q} 26.1 & \bullet ? \text { more often associated with a normal karyotype }\end{array}$

- Higher frequency of mutations in blast phase disease

- ? more often associated with a normal karyotype

DIPSS: Dynamic International Prognostic Scoring System; PMF: primary myelofibrosis; OS: overall survival; LFS: leukemia-free survival.

symptom burden and objective quality of life assessment. Given the marked intra-category heterogeneity, refinement of prognostication should occur with cytogenetic and mutational data and the patient should be counseled appropriately, particularly if high molecular risk features are present. Certainly, acquisition of high-risk karyotypes, transfusion dependence or steadily increasing peripheral blood blast counts would suggest a trigger to move towards allogeneic SCT.

\section{Recipient age: does this play a role in the transplant decision?}

The majority of prognostic scoring systems incorporate age as a risk factor; however, multiple dynamic factors determine post-transplant outcome (Figure 1). One of the most common questions is how old is 'too old'? Transplantation may be more challenging for elderly recipients and there is marked variation globally in the arbitrary age 'cut-off' for allogeneic SCT for myelofibrosis. Historically, many earlier studies suggested worse outcome with increasing age. For example, early myeloablative conditioning (MAC) studies involving total body irradiation demonstrated worse outcome for those patients $>45$ years old, and other small studies suggested worse outcomes for those $>50$ and $>60$ years old..$^{25-27}$ In contrast, the Seattle group reported on a highly selected group of myelofibrosis patients undergoing allogeneic SCT with a median age of 65 years (range, 60-78 years), many of whom had multiple co-morbidities. ${ }^{28}$ Time to engraftment and graft-versus-hostdisease (GvHD) rates did not differ significantly from those in younger cohorts. Moreover, no significant outcome differences were identified when comparing patients $<65$ years old with those $>65$ years old. Focusing on chronological age alone may not be correct and well-selected elderly patients with minimal co-morbidities and good organ function can benefit significantly from allogeneic SCT. However, real-life decisions can be more difficult in those $>70$ years old or in those individuals aged 65-70 years who have co-morbidities. In some cases, potential candidates may be frail because of disease symptom burden and have a worse Performance Status, a history of thrombosis or significant potential for hepatic dysfunction. These factors need careful consideration and optimization where possible. As described above, an upper age limit of 70 years was cautiously suggested but this does not mean that 'fit' individuals within a few years above this threshold should be excluded. In general, the transplant decision is heavily influenced by careful assessment of the patient and a multi-disciplinary approach. Moreover, factors incorporated in the comprehensive geriatric assessment should be considered and this requires validation in the setting of patients with myelofibrosis undergoing allogeneic SCT. ${ }^{29}$

\section{Is there a role for splenectomy before transplantation for myelofibrosis?}

Evidence on the beneficial role of splenectomy prior to allogeneic SCT remains somewhat sparse although in theory splenectomy may be an attractive strategy as it could 


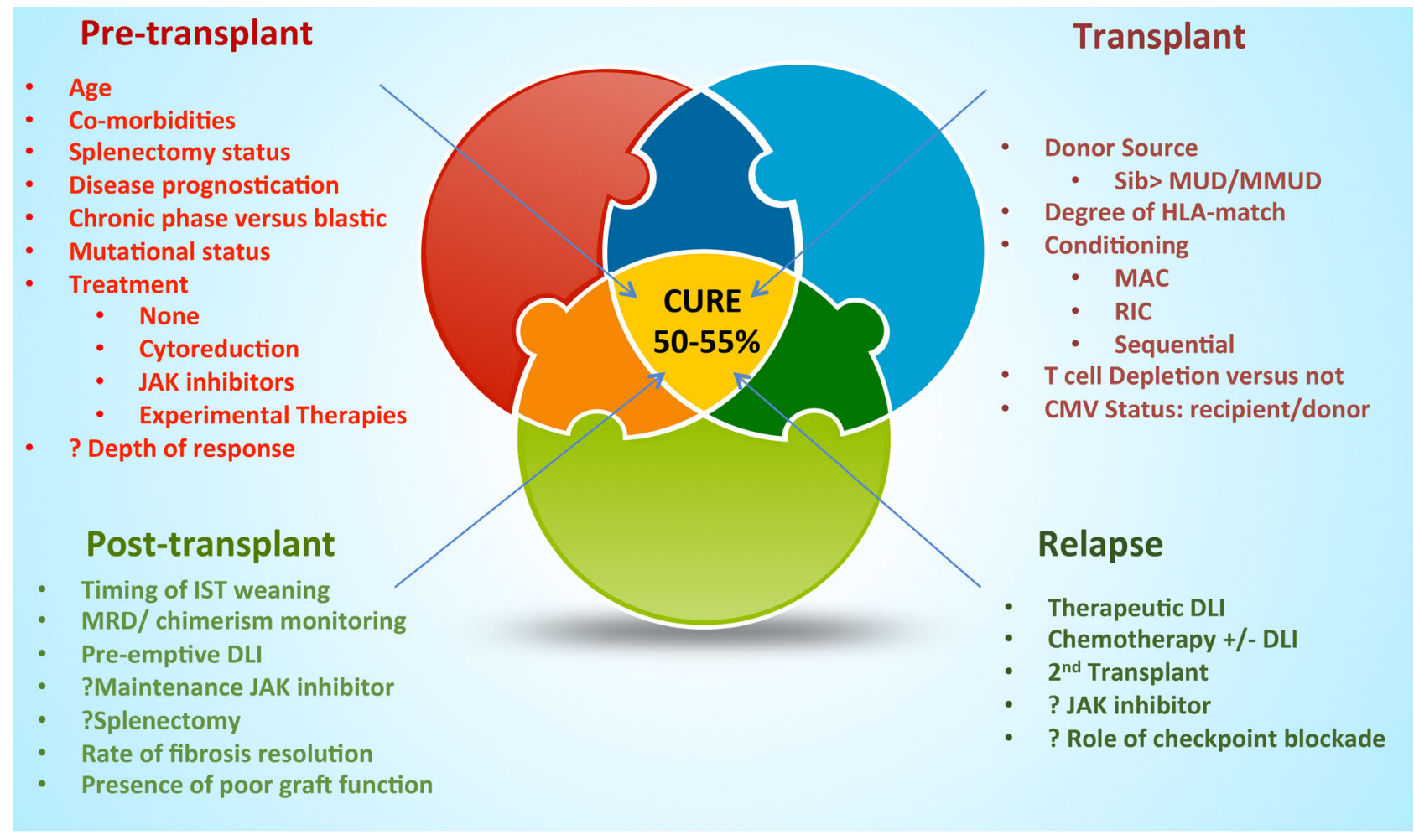

Figure 1. Factors determining outcomes following allogeneic stem cell transplantation in myelofibrosis. The determinants of outcomes following allogeneic stem cell transplantation can be divided into: pre-transplantation, transplant-specific, and post-transplant strategies and relapse management. IPSS: International Prognostic Scoring System; DIPSS: dynamic IPSS; IST: immunosuppressive therapy; DLI: donor lymphocyte infusion; MRD: minimal residual disease; Sib: sibling; MUD: matched unrelated donor; MMUD: mismatched unrelated donor; MAC: myeloablative conditioning; RIC: reduced Intensity conditioning; CMV: cytomegalovirus

aid engraftment and perhaps be associated with improved post-transplant outcome. ${ }^{30}$ However, this procedure is not without risk. Over a decade ago, the Mayo clinic group reported on 314 myelofibrosis patients, albeit not transplant candidates, undergoing elective splenectomy: the intervention was associated with significant perioperative complications in nearly $28 \%$ of cases. ${ }^{31}$ Despite major improvements with minimally invasive approaches, there are still potential risks of both thrombosis and hemorrhage. Although a prospective study of 103 patients undergoing allogeneic SCT coordinated by the Chronic Malignancies Working Party of the EBMT suggested more rapid neutrophil engraftment in those who had undergone splenectomy $(n=14)$ compared to those who had not, both univariate and multivariate analyses suggested a significantly higher rate of relapse at 3 years for the former. ${ }^{32}$ Moreover, effects on immune reconstitution and GvHD modulation are unclear. In contrast, a French group retrospectively reported on 85 myelofibrosis allogeneic SCT patients from a single center, 39 of whom had undergone pre-transplant splenectomy. ${ }^{33}$ Of note, one half of those patients undergoing splenectomy had surgical or post-surgical complications, most frequently of a thrombotic or hemorrhagic nature. Following Cox adjustment analyses, there was no association between pre-transplant splenectomy and either nonrelapse mortality (NRM) or relapse risk, in fact there was a suggestion towards improved overall survival and eventfree survival. This evidently requires evaluation in a larger cohort and ideally in a controlled study as suggested by the authors. In contrast to these findings, initial analyses by
McLornan et al. found no significant effect of splenectomy on overall survival or NRM in a large cohort of splenectomized patients undergoing allogeneic SCT with either reduced intensity conditioning (RIC) or MAC $(n=180)$ registered in the EBMT registry database and nor did the retrospective Center for International Blood and Marrow Transplant Research (CIBMTR) study. ${ }^{34,35}$ Moreover, given the potential splenic effects of JAK inhibitor therapy, alternative methods of reducing bulky splenomegaly are possible. Lastly, it is unknown what effect pre-transplant spleen removal will have on immune reconstitution. In general, it is the view of the authors that pre-transplant splenectomy cannot be routinely recommended although it is clear that individual patient-stratified assessment should occur. Lowdose splenic irradiation prior to transplantation has been explored in small cohorts of patients, but overall there is insufficient evidence on this strategy. ${ }^{36,37}$

\section{What is the role of JAK inhibitors before transplantation for myelofibrosis?}

Many questions arise from the use of JAK inhibitors in the myelofibrosis transplant algorithm. Following the phase III trials, COMFORT-I and -II, confirming the efficacy of the JAK1/JAK2 inhibitor ruxolitinib (Novartis, Switzerland) in myelofibrosis, many potential allogeneic SCT recipients have been treated with this agent. 5 JAK inhibitors collectively are attractive agents given that they may improve Performance Status, reduce splenomegaly and potentially shorten time to engraftment and may dampen an inherently pro-inflammatory milieu. Earlier and more recent studies 
Table 2. Summary of outcomes in the main studies on reduced intensity and myeloablative conditioning in myelofibrosis.

\begin{tabular}{|c|c|c|c|c|c|c|c|}
\hline Conditioning intensity & N. & Conditioning regimen & \multicolumn{2}{|c|}{ GvHD rates } & Overall survival & Comments & Reference \\
\hline RIC & 66 & $\begin{array}{c}\text { Flu Mel (sibling) } \\
\text { Flu Mel + ATG (URD) }\end{array}$ & \multicolumn{2}{|c|}{$\begin{array}{c}\text { Acute grade II-IV } \\
\text { Sibling } 38 \% \\
\text { URD } 41 \%\end{array}$} & $\begin{array}{l}75 \% \text { sibling } \\
32 \% \text { URD }\end{array}$ & $\begin{array}{l}24 \% \text { graft failure in the URD } \\
\text { group }\end{array}$ & 49 \\
\hline RIC & 103 & Flu Bu & \multicolumn{2}{|c|}{$\begin{array}{l}\text { Acute grade II-IV 26\% } \\
\text { Chronic L:24\%; E:24\% }\end{array}$} & $67 \%$ at 5 years & $\begin{array}{l}\text { Low rates of graft failure and } \\
\text { timely engraftment }\end{array}$ & 32 \\
\hline MAC & $\begin{array}{l}170 \text { Sibling } \\
117 \text { MUD } \\
33 \text { Other }\end{array}$ & Various & $\begin{array}{c}\text { Acute } \\
43 \% \\
40 \% \\
24 \%\end{array}$ & $\begin{array}{c}\text { Chronic } \\
\quad 40 \% \\
32 \% \\
26 \%\end{array}$ & $\begin{array}{l}39 \% \text { at } 5 \text { years } \\
31 \% \text { at } 5 \text { years } \\
31 \% \text { at } 5 \text { years }\end{array}$ & $\begin{array}{l}\text { Heterogeneous cohort; disease- } \\
\text { free survival long-term in } \\
\text { approximately } 1 / 3\end{array}$ & 35 \\
\hline Predominantly MAC & 104 & $\begin{array}{c}\text { TBI based }(n=15) \\
\text { Busulphan based }(n=80) \text {; } \\
\text { RIC }(n=9)\end{array}$ & \multicolumn{2}{|c|}{$\begin{array}{l}\text { Acute grade II-IV: } 64 \% \\
\text { Chronic L+E: } 84 \%\end{array}$} & $61 \%$ at 7 years & $\begin{array}{l}\text { Improved survival with } \\
\text { targeted busulfan } \\
\text { dosing in BuCy }\end{array}$ & 46 \\
\hline RIC & 233 & $\begin{array}{l}\text { Flu Bu (38\%) } \\
\text { Flu Mel }(28 \%) \\
\text { Flu TBI. (22\%) }\end{array}$ & \multicolumn{2}{|c|}{$\begin{array}{l}\text { Acute grade II-IV : } 37 \% \\
\text { Chronic at } 1 \text { year } 42 \%\end{array}$} & $\begin{array}{l}56 \% \text { for MSD, } \\
\text { 37\% URD, } \\
34 \% \text { MMUD }\end{array}$ & $\begin{array}{l}\text { Donor type most important } \\
\text { determinant of outcome }\end{array}$ & 77 \\
\hline RIC & 66 & $\begin{array}{l}\text { Flu Bu } \\
\text { FBM } \\
\text { Flu Mel }\end{array}$ & \multicolumn{2}{|c|}{$\begin{array}{c}\text { Acute grade II-IV } \\
47 \% \\
68 \% \\
68 \%\end{array}$} & $\begin{array}{c}\text { Similar OS, NRM } \\
\text { and relapse rates }\end{array}$ & $\begin{array}{l}100 \% \text { donor chimerism was } \\
\text { seen more frequently at } \\
\text { day }+30 \text { and day }+100 \text { in } \\
\text { patients who received } \\
\text { FBM or Flu Mel than Flu Bu. }\end{array}$ & 78 \\
\hline RIC & 160 & $\begin{array}{l}\text { Flu Bu (105) } \\
\text { Flu Mel (55) }\end{array}$ & $\begin{array}{r}\text { Acute } \\
31 \% \\
53 \%\end{array}$ & $\begin{array}{l}\text { Chronic } \\
62 \% \\
49 \%\end{array}$ & $\begin{array}{l}\text { 7-year OS was 52\% for } \\
\text { the Flu Mel group and } \\
59 \% \text { for the Flu Bu group }\end{array}$ & $\begin{array}{c}\text { Flu Mel regimen appears } \\
\text { to induce more NRM than } \\
\text { the Flu Bu regimen; but } \\
\text { with augmented disease } \\
\text { control; similar outcomes. }\end{array}$ & 48 \\
\hline $\begin{array}{l}\text { MAC } \\
\text { RIC }\end{array}$ & $\begin{array}{l}760 \\
1423\end{array}$ & $\begin{array}{l}\text { Common regimens } \\
\text { BuCy or TBI based } \\
\text { Flu Bu; Flu Mel }\end{array}$ & $\begin{array}{c}\text { Acute grade I-IV } \\
29 \% \\
32 \%\end{array}$ & $\begin{array}{l}\text { Chronic L/E } \\
23 / 27 \% \\
20 / 32 \%\end{array}$ & $\begin{array}{l}\text { Median } \mathrm{OS}=6.6 \text { years } \\
\text { Median } \mathrm{OS}=5.3 \text { years }\end{array}$ & $\begin{array}{c}\text { Primary analyses; full } \\
\text { analysis in preparation } \\
\text { No differences in NRM } \\
\text { between MAC/RIC } \\
\text { Worse outcome with MMUD and } \\
\text { poor Performance Status }\end{array}$ & 34 \\
\hline
\end{tabular}

ATG: antithymocyte globulin; Bu: busulfan; Cy: cyclophosphamide;E: extensive; FBM: fludarabine, bis-chlorethyl-nitroso-urea/carmustine, melphalan; Flu: fludarabine; GvHD: graft-versus-host disease; L: limited; MAC: myeloablative conditioning; Mel: melphalan; MMUD: mismatched unrelated donor; MUD: matched unrelated donor; NRM: non-relapse mortality; OS: overall survival; RIC: reduced intensity conditioning; TBI: total body irradiation; URD: unrelated donor

demonstrated that, in general, there were no serious adverse effects following the use of JAK inhibitors prior to allogeneic SCT with appropriate tapering. ${ }^{38-40}$ Of note the French phase II JAK ALLO trial, investigating the use of ruxolitinib before allogeneic SCT, was temporarily halted because of two cases of febrile cardiogenic shock and one of tumor lysis syndrome following ruxolitinib discontinuation. ${ }^{41}$ Subsequent experience has not demonstrated that either of these adverse events is common. Outcomes of 100 patients who had been exposed to JAK inhibitor therapy and underwent allogeneic SCT, between 2009-2014, were determined in a retrospective, multicenter study. ${ }^{42}$ The cohort was divided into five groups defined by clinical status/response to JAK inhibition: groups (i) clinical improvement ( $n=23)$, (ii) stable disease $(n=31)$, (iii) new cytopenia/increasing blasts/JAK inhibitor intolerance $(n=15)$, (iv) progressive disease: splenomegaly $(n=18)$, and (v) leukemic transformation $(n=13)$. The overall survival rate at 2 years after allogeneic SCT for the entire cohort was $61 \%$ (95\% CI: $49-71 \%)$. The cumulative incidence of grade II-IV acute GvHD by day 100 was 37\% (95\% CI: $27-47 \%$ ) and that of chronic GvHD by 2 years was $48 \%$. Survival analyses performed based on response to JAK inhibition prior to allogeneic SCT revealed a 2-year overall survival rate of $91 \%$ (95\% CI: $69-97 \%$ ) for patients with clinical improvement. However, it remains unclear whether the better post-transplant outcome in those achieving a clinical improvement was drug-related or simply reflected the presence of an inherently more favorable disease phenotype. A multicenter, German study reported on 159 patients, 46 of whom had received pre-transplant ruxolitinib at any point with a median treatment duration of 4.9 months (range, 0.4-39.1 months). ${ }^{43}$ There was a trend towards a lower rate of relapse in the ruxolitinib group ( $9 \%$ versus $17 \%, P=0.2$ ), with similar disease-free and overall survival rates. The hypothesis that pre-exposure to JAK inhibitors may modulate the relapse risk requires further exploration. In a recently published study of a small cohort of patients $(n=12)$ undergoing allogeneic SCT for myelofibrosis, ruxolitinib (5 mg BID) was continued until stable engraftment. ${ }^{44}$ There was no graft failure and timely neutrophil engraftment, although the drug had to be discontinued in two patients, on days +17 and +18 , because of post-engraftment cytopenia. Of particular relevance, the rate of grade II-IV acute GvHD within the first 100 days was low at $8 \%$ although the cytomegalovirus reactivation rate was $41 \%$. The use of peri-transplantation JAK inhibition to reduce the risk of GvHD remains an area of great interest. In conclusion, the 
majority of patients in 2018 who proceeded to allogeneic SCT had been exposed to JAK inhibitor therapy. The JAK inhibitor should be tapered down over a 10- to 14-day period so that JAK inhibition therapy is ceased just before the commencement of conditioning or prior to stem cell return. Whether the best strategy for patients receiving JAK inhibitor therapy with a view to allogeneic SCT is to undergo the transplant at the time of best response or whether the procedure should be delayed until a further trigger occurs remains difficult to determine and hence patientstratified approaches are required. Of note, JAK inhibitors are additionally becoming established in the treatment of steroid refractory GvHD, although this is outside the purpose of this review. ${ }^{45}$

\section{Conditioning intensity and regimen?}

Myeloablative conditioning for allogeneic stem cell transplantation in patients with myelofibrosis

Historically, the majority of MAC platforms consisted of total body irradiation with or without high-dose cyclophosphamide and early toxicity, NRM and GvHD rates were high, especially for older individuals. ${ }^{25,35}$ (Table 2). The large CIBMTR study reported on 289 patients who underwent allogeneic SCT between 1989 and 2002, 79\% of whom received MAC - predominantly busulfan + cyclophosphamide and total body irradiation with or without cyclophosphamide. ${ }^{25}$ The day +100 transplant-related mortality rate was $18 \%$ for those undergoing allogeneic SCT from an HLA-matched sibling and $35 \%$ for those receiving a graft from an unrelated donor. Approximately one-third of the patients achieved long-term (5 years) relapse-free survival. Kerbauy et al. reported on 104 patients, with a median age of 45 years (range, 18-70 years), 95 of whom received MAC. The NRM rate at 5 years was $34 \%$ and there were significant rates of acute grade II-IV GvHD (64\%) and chronic GvHD (84\%). ${ }^{46}$ The estimated 5year survival rate was $61 \%$ (95\% CI: $43-65 \%$ ) for the entire cohort. Those undergoing MAC with targeted levels of busulfan in combination with cyclophosphamide (120 $\mathrm{mg} / \mathrm{kg}$ ) had a significantly higher probability of overall survival (68\%). For younger recipients planned for MAC allogeneic SCT, our preference is towards busulfan + cyclophosphamide in an attempt to reduce therapy-related morbidity.

Reduced intensity conditioning for myelofibrosis allogeneic stem cell transplantation - what evidence exists to guide the choice of regimen?

Due to age distribution, the vast majority of patients undergoing transplantation will receive RIC. However, the term RIC covers a highly heterogeneous group of treatments as regards both immunosuppressive and moderate myeloablative properties. According to the EBMT consensus, RIC regimens are strictly defined as those which do not fit the definition for MAC or non-myeloablative regimens. ${ }^{47}$ Historically, published RIC platforms were admixed and reflected local practice (Table 2). The first prospective, EBMT multicenter phase II trial of RIC allogeneic SCT in myelofibrosis enrolled 103 patients between 2002-2007. ${ }^{32}$ Conditioning was uniform and consisted of busulfan (10 $\mathrm{mg} / \mathrm{kg}$ ) orally (or equivalent IV dose)/fludarabine (180 $\mathrm{mg} / \mathrm{m}^{2}$ ) and T-cell depletion achieved with antithymocyte globulin (Fresenius, Graefeling, Germany) at a dose of $3 \mathrm{x}$ $10 \mathrm{mg} / \mathrm{kg}$ (for related transplantation) or $3 \times 20 \mathrm{mg} / \mathrm{kg}$ (for unrelated donor transplantation). Primary graft failure rates were low $(\sim 2 \%)$ and timely engraftment of both neutrophils (median, 18 days; range, 10-84 days) and platelets $>20 \times 10^{9} / \mathrm{L}$ occurred (median, 22 days; range, 8 -145 days). Rates of acute GvHD were acceptable at $27 \%$ for grade IIIV and $11 \%$ for grade III-IV. The cumulative incidence of NRM at 1 year was $16 \%$ (95\% CI: 9-23\%) and was significantly higher in the mismatched donor setting than in the fully matched donor setting ( $38 \%$ versus $12 \% ; P=0.003$ ). The cumulative incidences of relapse at 3 and 5 years were acceptable at $22 \%$ and $29 \%$, respectively. Multivariate analysis suggested a higher 3-year relapse incidence with splenectomy (HR: 3.6) and Lille HR score (HR: 5.23). HLAmismatched transplantation was a risk factor for both therapy-related mortality and adverse overall survival. Updated survival analyses revealed estimated 5- and 8-year overall survival rates of $68 \%$ and $65 \%$, respectively. More recently, the two most frequently used RIC regimens for myelofibrosis - fludarabine-busulfan (FB) and fludarabine-melphalan (FM) were compared in a retrospective study of 160 patients (FB: $n=105, F M: n=55$ ) with a median follow up $>5$ years. ${ }^{48}$ Conditioning protocols were uniform, the FM regimen consisted of fludarabine $90 \mathrm{mg} / \mathrm{m}^{2}$ and melphalan 140 $\mathrm{mg} / \mathrm{m}^{2}$ and the FB regimen consisted of intravenous busulfan (or oral equivalent) $8 \mathrm{mg} / \mathrm{kg}$, fludarabine $180 \mathrm{mg} / \mathrm{m}^{2}$ and antithymocyte globulin-Fresenius ${ }^{\circledast}$. After statistical weighting, the incidence of acute GvHD was $62 \%$ for the FM group and $31 \%$ for the $\mathrm{FB}$ group while chronic $\mathrm{GvHD}$ rates were $49 \%$ and $53 \%$, respectively. Although the FM regimen had more pronounced early toxicity, the long-term outcome of patients treated with the two regimens was similar. Multivariate analysis failed to demonstrate significant differences regarding overall survival or disease-free survival although individuals undergoing FM conditioning had relapse rates of $<5 \%$. In both groups, the use of a HLAmismatched unrelated donor was associated with worse outcomes as regards NRM, overall survival and progression-free survival. A prospective, multicenter, phase II MPD-RC study investigated the use of FM conditioning in 66 patients recruited between 2007-2011. ${ }^{49}$ Those with sibling donors $(\mathrm{n}=32)$ received FM whereas those with unrelated donors $(n=34)$ received $F M+$ antithymocyte globulin. Significantly inferior results were seen with unrelated donors than with sibling donors: with a median follow up of 25 months, the overall survival rate was $75 \%$ in the sibling group compared to only $32 \%$ in the unrelated donor group (HR: 3.9; 95\% CI: 1.8-8.9; $P<0.001$ ). Moreover, considerable NRM rates were observed in the unrelated donor setting. Of note, this small study did not determine outcome differences between matched or mismatched unrelated donors, in contrast to other studies. ${ }^{32,34}$

Can we realistically compare myeloablative versus reduced intensity condition in allogeneic transplantation for myelofibrosis?

There are no current, prospective trials comparing RIC with MAC for myelofibrosis and conclusions from retrospective studies are not always straight forward. In a welldescribed cohort of 92 patients undergoing allogeneic SCT between 1982-2009, 40 patients received MAC and 52 RIC regimens. ${ }^{27}$ No differences existed with regards to day +100 transplant-related mortality. The probability of survival at 5 years was $49 \%$ for patients given MAC and $59 \%$ for those given RIC $(P=0.125)$. However, RIC platforms were associated with markedly improved outcome for those $<60$ years old compared to those who were older (estimated 5-year 
survival of $75 \%$ versus $20 \%$ ) and there was a lower incidence of acute GvHD with RIC regimens than with MAC. Almost 10 years ago, Patriarca et al. reported on the 20-year experience of the Gruppo Italiano Trapianto Di Midollo Osseo (GITMO) in which 48 patients underwent MAC and 52 were given RIC regimens..$^{50}$ Intensity of the conditioning regimen did not significantly influence either overall survival or relapse incidence. More recently, a preliminary analysis from the CMWP of the EBMT by McLornan et al. reported on a total of 2,183 patients who underwent allogeneic SCT for myelofibrosis; regimen intensity was assessed by standard EBMT criteria. ${ }^{34}$ Conventional MAC regimens were utilized in 760 patients while 1,423 received RIC regimens. Donor sources were similar: MAC cohort, $309(41 \%)$ matched sibling donors and 451 (59\%) unrelated donors; RIC cohort, 543 (38\%) matched sibling donors and $880(62 \%)$ unrelated donors. In the preliminary analyses, no statistically significant differences in engraftment, GvHD, NRM, progression-free survival and overall survival rates were found between these two large RIC and MAC cohorts; the final multivariate analysis is awaited. Lastly, the exact role of T-cell depletion strategies in allogeneic SCT for myelofibrosis requires clarification. In addition to the above discussions, retrospective analyses by Robin et al., on behalf of EBMT, have demonstrated that in the matched sibling donor setting, use of antithymocyte globulin decreased acute GvHD rates without increasing the relapse risk. ${ }^{51}$

\section{Alternative donors}

\section{Mismatched related donor transplantation in myelofibrosis}

Until recently, overall experience remained restricted because of historical fears of graft rejection and GvHD and exclusion from clinical trials. The EBMT group recently described a retrospective study of 56 myelofibrosis patients (median age, 57 years; range, 38-72 years) who underwent mismatched related donor transplantation. ${ }^{52}$ In this cohort, $70 \%$ received $\mathrm{MAC}$ and $30 \%$ received RIC; the source of hematopoietic stem cells was bone marrow in $66 \%$ of cases and peripheral blood in 34\%. Conditioning approaches varied, reflecting the heterogeneous nature of this cohort, but the most commonly used was thiotepa, busulfan and fludarabine (TBF) and post-transplant cyclophosphamide. Encouragingly, neutrophil engraftment by day 28 was achieved by $82 \%$ of the cohort, at a median time of 21 (range, 19-23) days. Primary graft failure occurred in five patients and secondary graft failure in seven, with two patients dying before engraftment. The cumulative incidence of acute GvHD at day +100 was $28 \%$ for grade II-IV and $9 \%$ for grade III-IV disease. The cumulative incidence of chronic GvHD at 1 year was $45 \%$. The 1 - and 2 -year overall survival rates were $61 \%$ (range, $48-74 \%$ ) and $56 \%$ (range, $41-70 \%$ ), respectively. The cumulative incidence of relapse was $19 \%$ (range, $7-31 \%$ ) and the NRM was $38 \%$ (range, $24-51 \%$ ) at 2 years. The exact role of transplantation from mismatched related donors in myelofibrosis does, therefore, require further clarification but this study demonstrates that engraftment is feasible with acceptable rates of GvHD and overall survival, although cumulative NRM rates remain somewhat high.

\section{Umbilical cord blood stem cell transplantation}

In the setting of myelofibrosis, Takagi et al. initially reported on 14 patients who had undergone RIC umbilical cord blood transplantation, predominantly high-risk candidates with secondary acute myeloid leukemia. ${ }^{53}$ Neutrophil engraftment was achieved in the vast majority $(92 \%)$ at a median of 23 days and full donor chimerism, where evaluable, was rapidly achieved. Survival was poor with a 4 -year overall survival rate of only $28 \%$, perhaps not surprisingly given the high-risk population. More recently, a series of 35 umbilical cord blood transplant recipients (median age, 54 years), registered under EUROCORD, was reported: seven had developed blast phase myelofibrosis and almost half underwent splenectomy. ${ }^{54}$ The most common conditioning regimen was total body irradiation, cyclophosphamide and fludarabine (TCF). Cord blood units were 5/6 (23\%) and 4/6 (77\%) HLAmatched. Neutrophil engraftment was achieved in 28/35 patients at a median time of 30 days and a total of 14 patients displayed graft failure (4 underwent a second transplant procedure). The 2-year overall and event-free survival rates were $44 \%$ and $30 \%$ respectively. In the RIC setting, all recipients undergoing TCF conditioning achieved both neutrophil and platelet engraftment and there was an association between utilization of this regimen and improved event-free survival.

\section{Blast phase myelofibrosis and allogeneic stem cell transplantation}

Historically, the outcome of patients with blast phase myeloproliferative neoplasms has been extremely poor. A recent retrospective analysis of 410 patients with blast phase myeloproliferative neoplasms, not focusing on allogeneic SCT, revealed a sobering median survival of 3.5 months. ${ }^{55}$ Intensive chemotherapy resulted in complete remission or complete remission with incomplete count recovery rates of $35 \%$ and $24 \%$, respectively, and even following allogeneic SCT the 3-year survival rate was $32 \%$. This retrospective work suggested that allogeneic SCT has a role in improving short-term survival but durability of response remains under question although the authors did acknowledge that the overall cohort of patients who underwent allogeneic SCT was small. The EBMT group published data on 46 patients who underwent allogeneic SCT for blast phase myelofibrosis and confirmed the importance of achieving complete remission prior to transplantation, which was also demonstrated in a retrospective collaborative French study. ${ }^{56,57}$ The transplant-related mortality rate at 1 year was acceptable at $28 \%$ and the 3 -year progression-free and overall survival rates were $26 \%$ and $33 \%$, respectively. The impact of both karyotype and mutational landscape on determining outcomes following transplantation for blast phase myelofibrosis is an area of active research and consideration should be given to post-transplant maintenance strategies.

\section{Post-transplant outcomes and complications}

\section{Impact of mutations on transplant outcome}

Early studies investigating the impact of the mutational landscape on the outcomes of allogeneic SCT yielded conflicting results..$^{32,58}$ Retrospective studies revealed a significant adverse impact of lack of the $J A K 2^{\mathrm{V} 617 \mathrm{~F}}$ mutation on overall survival after allogeneic SCT for myelofibrosis whereas a CALR mutation was associated with improved overall survival and less NRM.59,60 The impact of more extensive mutational profiling was recently investigated in 
a large retrospective study. ${ }^{61} \mathrm{~A}$ targeted 16-gene panel was used to analyze a total of 169 patients (110 with primary myelofibrosis, 46 with secondary myelofibrosis and 13 in transformation). Multivariate analysis revealed that the presence of a CALR mutation was associated with favorable overall survival (HR: $0.448 ; P=0.03$ ) and progressionfree survival (HR: 0.393; $P=0.01)$, and reduced NRM (HR, $0.415 ; P=0.05)$. Additionally, both IDH2 and ASXL1 mutations were independent prognostic risk factors for reduced progression-free survival (HR: 5.451; $P=0.002$ and HR: 1.53; $P=0.008$, respectively). Interestingly, 'triple negativity' did not appear to have a significant effect on posttransplant outcomes in this cohort although the numbers analyzed were small. Overall, where possible and dependent on local facilities, we recommend that a targeted gene panel is used to determine the mutational risk profile.

\section{Poor graft function}

Despite initial engraftment, it is well established that poor graft function can be problematic and patients may remain transfusion dependent and/or require growth factor support for a considerable period. Alchalby et al. reported that the cumulative incidence of poor graft function was $17 \%$ in a cohort of 100 RIC allogeneic SCT patients and that the median onset of this complication was day +49 (range, 24-99 days). ${ }^{62}$ Poor graft function was defined by either two or three cytopenias (hemoglobin $<100 \mathrm{~g} / \mathrm{L}$, neutrophil count $<1.0 \times 10^{9} / \mathrm{L}$, platelet count $\left.<30 \times 10^{9} / \mathrm{L}\right)$ at day +30 after allogeneic SCT, with transfusion requirements in the presence of complete donor chimerism and an absence of severe GvHD/disease relapse. Persistence of significant splenomegaly at day +30 remained a significant risk factor for poor graft function and univariate analysis revealed an association with older recipient age, perhaps reflecting age-related changes in a hostile bone marrow niche. Poor graft function did not appear to influence survival. Of relevance, Hart et al. recently compared engraftment kinetics in a small cohort of acute myeloid leukemia and myelofibrosis allogeneic SCT recipients. ${ }^{63}$ Compared to the group with acute myeloid leukemia, the myelofibrosis patients had marked early clearance of hematopoietic stem cells due to early splenic pooling accompanied by a significant reduction in VCAM1 expression in the bone marrow niche which may well explain, in part, the observed early poor graft function. Whether JAK inhibitor-mediated reductions in splenomegaly will result in lower incidences of poor graft function remains undetermined. Judicious monitoring of chimerism and appropriate growth factor and transfusion support are necessitated by the recognition that some patients may require stem cell top up or consideration given to splenectomy if bulky splenomegaly persists.

\section{Measurable residual disease monitoring and donor lymphocyte infusion strategies}

Measurable residual disease (MRD) monitoring to guide weaning of immunosuppression with or without utilization of immunotherapeutic strategies has become well established in the setting of allogeneic SCT for myelofibrosis. Alchalby et al. demonstrated that clearance of detectable $J A K 2^{\mathrm{V} 617 \mathrm{~F}}$ after allogeneic SCT was associated with a significantly reduced risk of relapse..$^{59}$ Both $M P L$ and CALR mutations can be used as markers of MRD. ${ }^{64-65}$ More recently, the significance of $M R D$ was evaluated in a large, single-center cohort $(n=136)$, in which pre-transplant molecular profiling revealed $J A K 2^{\mathrm{V} 617 \mathrm{~F}}(\mathrm{n}=101), M P L(\mathrm{n}=4)$ and CALR $(\mathrm{n}=31)$ mutations. ${ }^{66}$ Individuals with a detectable mutation at either day +100 or day +180 had a significantly higher risk of clinical relapse at 5 years compared to those in whom molecular studies were negative (62\% versus $10 \%, P<0.001$ and $70 \%$ versus $10 \%, P<0.001$, respectively). Multivariate modeling revealed that detectable $M R D$ at day +180 and high-risk disease status were significant factors associated with higher relapse rates. MRD status and chimerism studies should be used in tandem to determine whether donor lymphocyte infusions are required. Kroger et al. described the use of both pre-emptive $(n=8)$ and salvage donor lymphocyte infusion $(n=9)$ regimens in 17 myelofibrosis patients undergoing allogeneic SCT, highlighting the utility of MRD monitoring for guiding donor lymphocyte infusions and that pre-emptive strategies take precedence over salvage approaches. ${ }^{6}$

\section{Relapse following allogeneic stem cell transplantation: is this still a significant clinical problem?}

Relapse remains a significant issue following allogeneic SCT for myelofibrosis. Longer term follow-up of the EBMT prospective study described above suggested relapse rates of up to $25 \%$ at 5 years. ${ }^{32}$ A more recent EBMT retrospective study by McLornan et al. investigated the management and outcomes of 202 relapsed patients. ${ }^{68}$ The overall median time to relapse was relatively short at 7 months (range, 1.4-111). Patients who relapsed early had significantly worse outcomes than those of patients who relapsed later. Management approaches to the relapse episode were heterogeneous and direct comparisons were not possible; however, there was a suggested benefit from adoptive immunotherapeutic approaches with donor lymphocyte infusions and/or a second allograft. There is some experience on the use of using JAK inhibitors following relapse to bridge to a second transplant and for symptom control but no improvements in donor chimerism or reductions in JAK2 allelic burden, where applicable, were seen. ${ }^{6}$ Pre-emptive use of JAK inhibitors in the post-transplant setting to reduce relapse incidence is of interest and requires prospective studies.

\section{Conclusions}

Rapid advances in the availability of novel therapeutic agents for myelofibrosis has made it increasingly complex to gauge the timing and sequencing of allogeneic SCT in the patient's care process. Nonetheless, allogeneic SCT remains the only curative approach for transplant-eligible patients. All available prognostic information and recent scoring systems should be utilized, including comprehensive mutational profiling where available, to stratify realistic patient-specific prognostic outcomes and assess the risk-benefit ratio. Changes in practice are required so that potential candidates are assessed by transplant physicians at an earlier stage, even if this is only to discuss and provide information about the procedure, assess fitness and identify potential donors. JAK inhibitors have become an integral part of the pre-allogeneic SCT pathway for many patients and increasing data on outcome analysis are now available. Overall, the use of these drugs prior to allogeneic SCT appears to be safe, with no adverse effects on engraftment; tapering is appropriate leading up to conditioning therapy and there is emerging data concerning 
potential reductions in the risks of $\mathrm{GvHD}$ and relapse, although these need confirmation. Alertness to potential infectious complications is warranted. How the role of other novel agents will fit into the transplant paradigm remains unknown. Current challenges regarding allogeneic SCT are to reduce the relapse risk and rates of NRM, particularly when using alternative donors, and optimization of graft function.

\section{References}

1. James C, Ugo V, Le Couédic JP, et al. A unique clonal JAK2 mutation leading to constitutive signalling causes polycythaemia vera. Nature. 2005;434(7037):1144-1148

2. Kralovics R, Passamonti F, Buser AS, et al. A gain-of-function mutation of JAK2 in myeloproliferative disorders. N Engl J Med. 2005;352(17):1779-1790.

3. Levine RL, Wadleigh M, Cools J, et al. Activating mutation in the tyrosine kinase JAK2 in polycythemia vera, essential thrombocythemia, and myeloid metaplasia with myelofibrosis. Cancer Cell. 2005;7(4),387-97

4. Baxter EJ, Scott LM, Campbell PJ, et al. Cancer Genome Project. Acquired mutation of the tyrosine kinase JAK2 in human myeloproliferative disorders. Lancet. 2005;365 (9464):1054-1061

5. Harrison C, Kiladjian JJ, Al-Ali HK, et al. JAK inhibition with ruxolitinib versus best available therapy for myelofibrosis. N Engl J Med. 2012;366(9):787-798

6. Verstovsek S, Mesa RA, Gotlib J, et al. A double-blind, placebo-controlled trial of ruxolitinib for myelofibrosis. N Engl J Med. 2012;366(9):799-807.

7. Bose P, Verstovsek S. Developmental therapeutics in myeloproliferative neoplasms. Clin Lymphoma Myeloma Leuk. 2017;17S:S43-S52.

8. Cervantes F, Dupriez B, Pereira A, et al. New prognostic scoring system for primary myelofibrosis based on a study of the International Working Group for Myelofibrosis Research and Treatment. Blood. 2009;113(13),2895-2901.

9. Passamonti F, Cervantes F, Vannucchi AM, et al. A dynamic prognostic model to predict survival in primary myelofibrosis: a study by the IWG-MRT (International Working Group for Myeloproliferative Neoplasms Research and Treatment). Blood. 2010;115(9):1703-1708.

10. Gangat N, Caramazza D, Vaidya R, et al. DIPSS-Plus: a refined Dynamic International Prognostic Scoring System (DIPSS) for primary myelofibrosis that incorporates prognostic information from karyotype, platelet count and transfusion status. J Clin Oncol. 2011;29(4):392-397.

11. Hussein K, Pardanani AD, Van Dyke DL, Hanson CA, Tefferi A. International Prognostic Scoring System-independent cytogenetic risk categorization in primary myelofibrosis. Blood. 2010;115(3):496-499.

12. Kröger NM, Deeg JH, Olavarria E, et al. Indication and management of allogeneic stem cell transplantation in primary myelofibrosis: a consensus process by an EBMT/ELN international working group. Leukemia. 2015;29(11):2126-2133.

13. Kröger N, Giorgino T, Scott BL, et al. Impact of allogeneic stem cell transplantation on survival of patients less than 65 years of age with primary myelofibrosis. Blood. 2015;125(21):3347-3350

14. Grinfeld J, Nangalia, J, Baxter EJ, et al. Personalized prognostic predictions for Patients with myeloproliferative neoplasms through integration of comprehensive genomic and clinical information. Blood. 2017;130(Suppl 1):491.

15. Passamonti F Giorgino T, Mora B, et al. A clinical-molecular prognostic model to predict survival in patients with post polycythemia vera and post essential thrombocythemia myelofibrosis. Leukemia. 2017;31 (12):2726-2731

16. Scott BL, Gooley $\mathrm{T}$, Linenberger $\mathrm{M}$, et al International Working Group scores predict post-transplant outcomes in patients with myelofibrosis. Blood. 2010;116(21):3085.

17. Scott BL, Gooley TA, Sorror M, et al. The Dynamic International Prognostic Scoring System for myelofibrosis predicts outcomes after hematopoietic cell transplantation. Blood. 2012;119(11):2657-2664

18. Gagelmann N, Eikema DJ, Koster L, et al. Comparative performance of prognostic systems in patients with myelofibrosis secondary to PV and ET after allogeneic stem-cell transplantation. EHA Meeting 2018;Abstract S129.

19. Rumi E, Pietra D, Pascutto C, et al. Clinical effect of driver mutations of JAK2, CALR, or MPL in primary myelofibrosis. Blood. 2014:124(7):1062-1069.

20. Tefferi A, Guglielmelli P, Lasho $\Pi$, et al. CALR and ASXL1 mutations-based molecular prognostication in primary myelofibrosis: an international study of 570 patients. Leukemia. 2014;28(7):1494-1500.

21. Tefferi A, Lasho TL, Finke C, et al. Type 1 vs type 2 calreticulin mutations in primary myelofibrosis: differences in phenotype and prognostic impact. Leukemia. 2014;28(7): 1568-1570

22. Guglielmelli P, Lasho TL, Rotunno G, et al The number of prognostically detrimental mutations and prognosis in primary myelofibrosis: an international study of 797 patients. Leukemia. 2014;28(9):1804-1810.

23. Guglielmelli P, Lasho TL, Rotunno G, et al. MIPSS70: Mutation-enhanced International Prognostic Score System for transplantationage patients wth primary myelofibrosis. Clin Oncol. 2018;36(4):310-318

24. Tefferi A, Guglielmelli P, Lasho TL, et al. MIPSS70+ version 2.0: mutation and karyotype-enhanced International Prognostic Scoring System for primary myelofibrosis. Clin Oncol. 2018:36(17): 1769-1770.

25. Guardiola P, Anderson J.E, Bandini G, et al. Allogeneic stem cell transplantation for agnogenic myeloid metaplasia: a European Group for Blood and Marrow Transplantation, Societe Francaise de Greffe de Moelle, Gruppo Italiano per il Trapianto del Midollo Osseo, and Fred Hutchinson Cancer Research Center collaborative study. Blood. 1999;93(9):2831-2838.

26. Nivison-Smith I, Dodds AJ, Butler J, et al. Allogeneic hematopoietic cell transplantation for chronic myelofibrosis in Australia and New Zealand: older recipients receiving myeloablative conditioning at increased mortality risk. Biol Blood Marrow Transplant. 2012;18(2):302 -308

27. Abelsson J, Merup M, Birgegard G, et al. The outcome of allo-HSCT for 92 patients with myelofibrosis in the Nordic countries. Bone Marrow Transplant. 2011;47(3):380-386.

28. Samuelson S, Sandmaier B.M, Heslop HE, et al. Allogeneic haematopoietic cell transplantation for myelofibrosis in 30 patients 60-78 years of age. Br J Haematol. 2011;153(1):7682.

29. Muffly LS, Kocherginsky M, Stock W, et al. Geriatric assessment to predict survival in older allogeneic hematopoietic cell transplantation recipients. Haematologica. 2014;99(8): 1373-1379

30. Robin M, Tabrizi R, Mohty $M$, et al Allogeneic haematopoietic stem cell transplantation for myelofibrosis: a report of the Société Française de Greffe de Moelle et de Thérapie Cellulaire (SFGM-TC). $\mathrm{Br}$ Haematol. 2011;152(3):331-339.

31. Mesa R.A, Nagorney D.S, Schwager S, Allred J, Tefferi A. Palliative goals, patient selection, and perioperative platelet management: outcomes and lessons from 3 decades of splenectomy for myelofibrosis with myeloid metaplasia at the Mayo Clinic. Cancer. 2006;107(2):361-370

32. Kroger N, Holler E, Kobbe G, et al Allogeneic stem cell transplantation after reduced-intensity conditioning in patients with myelofibrosis: a prospective, multicenter study of the Chronic Leukemia Working Party of the European Group for Blood and Marrow Transplantation. Blood. 2009:114 (26):5264-5270

33. Robin M, Zine M, Chevret $S$, et al. The impact of splenectomy in myelofibrosis patients before allogeneic hematopoietic stem cell transplantation. Biol Blood Marrow Transplant. 2017;23(6):958-964.

34. McLornan D, Szydlo R, Robin M, et al. Outcome of myeloablative and reducedintensity conditioned allogeneic haematopoietic stem cell transplantation in myelofibrosis: a retrospective study by the Chronic Malignancies Working Party of the EBMT. Annual EBMT meeting. 2018; OS 5-5

35. Ballen KK, Shrestha S, Sobocinski KA, et al. Outcome of transplantation for myelofibrosis. Biol Blood Marrow Transplant. 2010;16(3):358-367.

36. Matsubara E, Yamanouchi J, Kitazawa R, et al. Usefulness of low-dose splenic irradiation prior to reduced-intensity conditioning regimen for hematopoietic stem cell transplantation in elderly patients with myelofibrosis. Case Rep Hematol. 2016:2016:8751329.

37. Kalman NS, Mukhopadhyay ND, Roberts $\mathrm{CH}$, et al. Low-dose splenic irradiation prior to hematopoietic cell transplantation in hypersplenic patients with myelofibrosis Leuk Lymphoma. 2017;58(12):2983-2984.

38. Jaekel N, Behre G, Behning A, et al Allogeneic hematopoietic cell transplantation for myelofibrosis in patients pretreated with the JAK1 and JAK2 inhibitor ruxolitinib. Bone Marrow Transplant. 2014;49(2): 179184.

39. Stübig $T$, Alchalby $H$, Ditschkowski $M$, et al JAK inhibition with ruxolitinib as pretreatment for allogeneic stem cell transplantation in primary or post-ET/PV myelofibrosis. Leukemia. 2014;28(8):1736-1738 
40. Gupta V, Kosiorek HE, Mead A, Klisovic RB, et al. Ruxolitinib therapy followed by reduced-intensity conditioning for hematopoietic cell transplantation for myelofibrosis: myeloproliferative disorders research Consortium 114 study. Biol Blood Marrow Transplant. 2019;25(2):256-264.

41. Robin M, Francois S, Huynh A, et al. Ruxolitinib before allogeneic hematopoietic stem cell transplantation (HSCT) in patients with myelofibrosis: a preliminary descriptive report of the JAK ALLO study, a phase II trial sponsored by Goelams-FIM in collaboration with the SFGMTC. Blood, 2013;122(21):306.

42. Shanavas M, Popat U, Michaelis LC, et al. Outcomes of allogeneic hematopoietic cell transplantation in patients with myelofibrosis with prior exposure to Janus kinase 1/2 inhibitors. Biol Blood Marrow Transplant. 2016;22(3):432-440

43. Shahnaz Syed Abd Kadir S, Christopeit M, Gerald W, et al. Impact of ruxolitinib pretreatment on outcomes after allogeneic stem cell transplantation in patients with myelofibrosis. Eur J Haematol. 2018;101(3):305-317.

44. Kröger N, Shahnaz Syed Abd Kadir S, Zabelina T, et al. Peritransplantation ruxolitinib prevents acute graft-versus-host disease in patients with myelofibrosis undergoing allogenic stem cell transplantation. Biol Blood Marrow Transplant. 2018;24(10): 2152-2156.

45. Zeiser R, Burchert A, Lengerke C, et al. Ruxolitinib in corticosteroid-refractory graftversus-host disease after allogeneic stem cell transplantation: a multicenter survey. Leukemia. 2015:29(10):2062-2068.

46. Kerbauy DM, Gooley TA, Sale GE, et al. Hematopoietic cell transplantation as curative therapy for idiopathic myelofibrosis, advanced polycythemia vera, and essential thrombocythemia. Biol Blood Marrow Transplant. 2007;13(3):355-365

47. Bacigalupo A, Ballen K, Rizzo D, et al. Defining the intensity of conditioning regimens: working definitions. Biol Blood Marrow Transplant. 2009;15(12):1628-1633.

48. Robin M, Porcher R, Wolschke C, et al. Outcome after transplantation according to reduced-intensity conditioning regimen in patients undergoing Transplantation for Myelofibrosis. Biol Blood Marrow Transplant. 2016;22(7):1206-1211.

49. Rondelli D, Goldberg JD, Isola L, et al. MPDRC 101 prospective study of reduced-intensity allogeneic hematopoietic stem cell transplantation in patients with myelofibrosis. Blood. 2014:124(7):1183-1191.

50. Patriarca F, Bacigalupo A, Sperotto A, et al. Allogeneic hematopoietic stem cell transplantation in myelofibrosis: the 20-year experience of the Gruppo Italiano Trapianto di Midollo Osseo (GITMO). Haematologica. 2008:93(10):1514-1522.

51. Robin M, Chevret S, Koster L, et al. In vivo $\mathrm{T}$ cell depletion in patients with myelofibrosis transplanted from an HLA-matched sibling donor: an EBMT study. 44th Annual Meeting of the European Society for Blood and Marrow Transplantation: Physicians Oral Session: Bone Marrow Transplant. 2018 Abstract supplements.

52. Raj K, Eikema DJ, McLornan DP, et al. Family mismatched allogeneic stem cell transplanta- tion for myelofibrosis: report from the Chronic Malignancies Working Party of EBMT. Biol Blood Marrow Transplant. 2018 Nov5. [Epub ahead of print]

53. Takagi S, Ota Y, Uchida N, et al. Successful engraftment after reduced intensity umbilical cord blood transplantation for myelofibrosis. Blood. 2010;116(4):649-652

54. Robin M, Giannotti F, Deconinck E, et al. Unrelated cord blood transplantation for patients with primary or secondary myelofibrosis. Biol Blood Marrow Transplant. 2014;20(11):1841-1846.

55. Tefferi A, Mudireddy M, Mannelli F, et al. Blast phase myeloproliferative neoplasm: Mayo-AGIMM study of 410 patients from two separate cohorts. Leukemia. 2018; 32(5):1200-1210.

56. Alchalby $\mathrm{H}$, Zabelina $\mathrm{T}$, Stübig $\mathrm{T}$, et al Allogeneic stem cell transplantation for myelofibrosis with leukemic transformation: a study from the Myeloproliferative Neoplasm Subcommittee of the CMWP of the European Group for Blood and Marrow Transplantation. Biol Blood Marrow Transplant. 2014;20(2): 279-281.

57. Cahu X, Chevallier P, Clavert A, et al. AlloSCT for Philadelphia-negative myeloproliferative neoplasms in blast phase: a study from the Societe Française de Greffe de Moelle et de Therapie Cellulaire (SFGM-TC). Bone Marrow Transplant. 2014;49(6):756-760.

58. Ditschkowski M, Elmaagacli AH, Trenschel R, Steckel NK, Koldehoff M, Beelen DW. No influence of V617F mutation in JAK2 on outcome after allogeneic hematopoietic stem cell transplantation (HSCT) for myelofibrosis. Biol Blood Marrow Transplant. 2006;12(12):1350-1351.

59. Alchalby H, Badbaran A, Zabelina $\mathrm{T}$, et al. Impact of JAK2V617F mutation status, allele burden, and clearance after allogeneic stem cell transplantation for myelofibrosis. Blood. 2010;116(18):3572-3581.

60. Panagiota V, Thol F, Markus B, et al Prognostic effect of calreticulin mutations in patients with myelofibrosis after allogeneic hematopoietic stem cell transplantation. Leukemia. 2014:28(7):1552-1555.

61. Kröger N, Panagiota V, Badbaran A, et al. Impact of molecular genetics on outcome in myelofibrosis patients after allogeneic stem cell transplantation. Biol Blood Marrow Transplant. 2017;23(7):1095-1101

62. Alchalby $\mathrm{H}$, Yunus DR, Zabelina T, Ayuk F, Kröger $\mathrm{N}$. Incidence and risk factors of poor graft function after allogeneic stem cell transplantation for myelofibrosis. Bone Marrow Transplant. 2016;51(9):1223-1227.

63. Hart C, Klatt S, Barop J, et al. Splenic pooling and loss of VCAM-1 causes an engraftment defect in patients with myelofibrosis after allogeneic hematopoietic stem cell transplantation. Haematologica 2016;101 (11):1407-1416.

64. Alchalby H, Badbaran A, Bock O, et al. Screening and monitoring of MPL W515L mutation with real-time PCR in patients with myelofibrosis undergoing allogeneicSCT. Bone Marrow Transplant. 2010;45(9): 1404-1407

65. Rumi E, Passamonti F, Arcaini L, et al. Molecular remission after allo-SCT in a patient with post-essential thrombo- cythemia myelofibrosis carrying the MPL (W515A) mutation. Bone Marrow Transplant. 2010;45(4):798-800.

66. Wolschke C, Badbaran A, Zabelina T, et al Impact of molecular residual disease post allografting in myelofibrosis patients. Bone Marrow Transplant. 2017;52(11):1526-1529.

67. Kroger N, Alchalby H, Klyuchnikov E, et al. JAK2-V617F- triggered pre-emptive and salvage adoptive immunotherapy with donorlymphocyte infusion in patients with myelofibrosis after allogeneic stem cell transplantation. Blood. 2009;113(8):18661868

68. McLornan DP, Szydlo R, Robin M, et al. Outcome of patients with myelofibrosis relapsing after allogeneic stem cell transplant: a retrospective study by the Chronic Malignancies Working Party of EBMT. Br J Haematol. 2018 May 29. [Epub ahead of print]

69. Janson D, Ayuk F. A, Wolschke C, et al Ruxolitinib for myelofibrosis patients relapsing after allogeneic hematopoietic transplantation. Blood. 2016;128(22):1948.

70. Lasho TL, Jimma T, Finke CM, et al. SRSF2 mutations in primary myelofibrosis: significant clustering with IDH mutations and independent association with inferior overal and leukemia-free survival. Blood. 2012;120(20):4168-4171.

71. Tefferi A, Finke CM, Lasho TL et al. U2AF1 mutations in primary myelofibrosis are strongly associated with anemia and thrombocytopenia despite clustering with JAK2V617F and normal karyotype Leukemia. 2014:28(2):431-433.

72. Tefferi A, Lasho TL, Finke CM, et al. CALR vs JAK2 vs MPL-mutated or triple-negative myelofibrosis: clinical, cytogenetic and molecular comparisons. Leukemia. 2014;28(7):1472-1477.

73. Lasho TL, Finke CM, Hanson CA, et al. SF3B1 mutations in primary myelofibrosis: clinical, histopathology and genetic correlates among 155 patients. Leukemia. 2012;26(5):1135-1137.

74. Tefferi A, Lasho TL, Finke C, et al. Prognostic significance of ASXL1 mutation types and allele burden in myelofibrosis. Leukemia. 2018;2(3):837-839.

75. Guglielmelli P, Biamonte F, Score I, et al EZH2 mutational status predicts poor survival in myelofibrosis. Blood. 2011;118(19): 5227-5234.

76. Tefferi A, Jimma T, Sulai NH, et al. IDH mutations in primary myelofibrosis predict leukemic transformation and shortened survival: clinical evidence for leukemogenic collaboration with JAK2V617F. Leukemia. 2012;26(3):475-480.

77. Gupta V, Malone AK, Hari PN, et al Reduced-intensity hematopoietic cell transplantation for patients with primary myelofibrosis: a cohort analysis from the center for international blood and marrow transplant research. Biol Blood Marrow Transplant. 2014;20(1):89-97.

78. Jain $\mathrm{T}$, Kunze $\mathrm{KL}$, Temkit $\mathrm{M}$, et al Comparison of reduced intensity conditioning regimens used in patients undergoing hematopoietic stem cell transplantation for myelofibrosis. Bone Marrow Transplant. 2019;54(2):204-211. 